\title{
Measures of cardiovascular autonomic nervous function: agreement, reproducibility, and reference values in middle age and elderly subjects
}

\author{
J. Gerritsen'1, B. J. TenVoorde1, J. M. Dekker ${ }^{2,4}$, R. Kingma ${ }^{1}$, P. J. Kostense ${ }^{2,3}$, L. M. Bouter ${ }^{2}$, R. M. Heethaar ${ }^{1}$ \\ ${ }^{1}$ Department of Clinical Physics and Informatics, Vrije Universiteit medical centre, Amsterdam, The Netherlands \\ ${ }^{2}$ Institute for Research in Extramural Medicine, Vrije Universiteit medical centre Amsterdam, The Netherlands \\ ${ }^{3}$ Department of Clinical Epidemiology and Biostatistics, Vrije Universiteit medical centre Amsterdam, The Netherlands \\ ${ }^{4}$ On behalf of the Hoorn Study Research Group: L.M. Bouter, J.M. Dekker, R.J. Heine, G. Nijpels, C.D.A. Stehouwer, \\ Vrije Universiteit medical centre Amsterdam, The Netherlands
}

\begin{abstract}
Aims/hypothesis. Currently, three categories of cardiovascular autonomic nervous function measures are used: classic Ewing-test measures, measures of heartrate variability (HRV), and measures of baroreflex sensitivity (BRS). Little is known about the agreement between these measures, and reference and reproducibility values for these measures have not been reported within the same group.

Methods. As part of the Hoorn Study, 631 subjects aged 50 to 75 participated in a study of autonomic nervous function. Cardiac cycle duration (RR interval) and continuous finger arterial pressure were measured under three conditions: during spontaneous breathing, during six deep breaths over $1 \mathrm{~min}$, and during an active change in position from lying to standing. From these readings, ten measures of autonomic function were assessed (mean heart rate, three Ewing test measures, five HRV measures and one BRS measure).

Results. Regression analysis in a healthy subgroup $(n=191)$ showed sex differences for two of the ten
\end{abstract}

measures and seven measures decreased with age. Therefore, appropriate age-specific and sex-specific reference values were calculated. Reproducibility $(n=39)$ of most measures was moderate, with a reliability coefficient of around 50\%. Agreement between the measures of autonomic nervous function varied greatly, between $0 \%$ and $87 \%$. The HRV-power ratio measure and the blood pressure changes in the lyingto-standing test showed the lowest agreement with all other measures.

Conclusion/Interpretation. This study provides agespecific and sex-specific reference values for $a$ wide range of different autonomic function measures in an elderly population. Agreement among the different measures varied widely and reproducibility was only moderate. [Diabetologia (2003) 46:330-338]

Keywords Aging, agreement, baroreflex, diabetes mellitus, heart-rate variability, nervous system, autonomic, reference values, reproducibility.
Received: 6 August 2002 / Revised: 13 November 2002 Published online: 18 March 2003

(C) Springer-Verlag 2003

Corresponding author: B. J. TenVoorde $\mathrm{PhD}$, Department of Clinical Physics and Informatics, Vrije Universiteit medical centre, P.O. Box 7057, 1007 MB Amsterdam, The Netherlands E-mail: bj.voorde@vumc.nl

Abbreviations: BRS, Baroreflex sensitivity ( $\mathrm{ms} / \mathrm{mmHg}$ ); DM, Diabetes mellitus; EI difference, Expiration-inspiration difference in RR intervals during breathing at $6 / \mathrm{min}$ (ms); HRV, Heart-rate variability; HF power, High frequency power in the RR-interval spectrum between $0.12-0.40 \mathrm{~Hz}\left(\mathrm{~ms}^{2}\right)$; KDM, Known diabetes mellitus; LF power, Low-frequency power in the RR-interval spectrum between $0.04-0.12 \mathrm{~Hz}\left(\mathrm{~ms}^{2}\right)$; $\mathrm{LF} /(\mathrm{LF}+\mathrm{HF})$, Ratio of low frequency power to the sum of low and high frequency power in the RR-interval spectrum; Mean NN, Mean of all sinus rhythm (normal-to-normal) RR intervals (ms); NDM, Newly-diagnosed diabetes mellitus; NGT, Normal glucose tolerance; RRmax, Maximal change in RR interval after standing up (ms); RRmax/min, Maximal RR interval between $15 \mathrm{~s}$ and $30 \mathrm{~s}$ after standing up divided by the minimal RR interval within $15 \mathrm{~s}$ after standing up; SBP difference, Systolic blood pressure 1.5-2 minutes after standing up minus systolic blood pressure in supine position $(\mathrm{mmHg})$; SDNN, Standard deviation of all sinus rhythm (normal-to-normal) RR intervals (ms). 
Autonomic changes in the heart and cardiovascular system in diabetes mellitus occur as part of the wider spectrum of autonomic neuropathy, which affects most organs of the body, e.g. the gastrointestinal and the genitourinary tracts, the sudomotor system involved in sweat production, the eyes and the endocrine organs. It is in the cardiovascular system that involvement of the autonomic nervous system is most noticeable and most easily assessed. Abnormalities can be detected in an early, asymptomatic phase and in a non-invasive way. Therefore, cardiovascular autonomic function tests could play an important role in the early detection of (diabetic) autonomic neuropathy. To some extent consensus was obtained in the past on a number of tests to assess cardiovascular autonomic function [1, 2]: the so-called Ewing battery [3]. In addition, heart-rate variability (HRV) and, more recently, the sensitivity of spontaneous baroreflex control of the heart rate (baroreflex sensitivity, BRS), have been used to assess autonomic dysfunction as well. It has been proposed that these measures might be even more sensitive than the Ewing battery $[4,5,6,7]$.

Among the standard cardiovascular autonomic function tests, i.e. the Ewing battery, are the deep breathing test, the lying-to-standing test, the Valsalva manoeuvre and the sustained handgrip test [3]. These Ewing test measures, and also HRV and BRS measures, are based on the autonomically mediated response of the heart rate to changes in blood pressure. Autonomic function has been reported to decrease in relation to age $[8,9,10,11,12,13]$ and to differ between men and women $[9,14,15]$. Furthermore, diabetic patients have lower values on the Ewing battery $[3,16,17,18,19]$, of the spectral analysis of HRV [4, $16,20,21]$, and have a low BRS [5, 22] in comparison with normal glucose tolerant control subjects. Besides their application in the assessment of cardiovascular autonomic function in diabetic patients, HRV and BRS are used in cardiology for risk stratification after myocardial infarction. Low HRV is associated with mortality risk in post-myocardial infarction patients $[23,24]$ and also in the general population [25, 26]. Also, autonomic neuropathy has been proposed to play a role in the aetiology of cardiovascular disease $[27,28,29,30,31]$ and nephropathy $[32,33]$ in diabetes. So far, the agreement between the autonomic functions tests, their reproducibility and reference values have not been reported in a single study. This information will be valuable for clinical practice [34].

\section{Subjects and methods}

Study population: reference values and agreement. The Hoorn Study is a prospective study of glucose tolerance and cardiovascular risk factors in a 50 to 75 -year-old general Caucasian population $[35,36,37,38]$. In short, an age-, sex- and glucosetolerance-stratified sample of 708 subjects out of a cohort of 2484 was invited for a second 75 -gram oral glucose tolerance test within 3 to 5 weeks and requested to undergo an extensive physical examination, including autonomic function tests, on another day. Of this sample, $631(89 \%)$ participated. Subjects were classified according to the WHO criteria, based on the mean values of the two oral glucose tolerance tests [39]: 288 had normal glucose tolerance (NGT), 169 had impaired glucose tolerance (IGT), 95 had newly diagnosed diabetes (NDM), and 79 subjects were known Type 2 diabetic patients (KDM). For evaluating reference values only subjects with a normal glucose tolerance were included. In addition, subjects were excluded because of a self-reported history of neurological disease (5 subjects), self-reported chronic obstructive pulmonary disease (4 subjects), a history of cardiovascular disease (40 subjects) as assessed by means of a Dutch translation of the London School of Hygiene and Tropical Medicine questionnaire [40]. Hypertensive subjects were also excluded; hypertension was defined as current treatment with antihypertensive drugs (49 subjects), mean systolic blood pressure greater than or equal to $160 \mathrm{mmHg}$, and/or mean diastolic blood pressure greater than or equal to $95 \mathrm{mmHg}$ (36 subjects) based on four blood pressure measurements. This resulted in a study sample of 191 healthy subjects for the computation of the reference values. For the computation of agreement, the data from the complete study sample of 631 subjects were used. Of the 631 initial subjects, 43 were invited to participate in a reproducibility study. The subjects were not selected on health status, but were chosen in such a way to have a wide range of ages and to have both normal glucose tolerance and diabetes. Of the subjects 39 responded, and had a second set of measurements taken within 3 weeks.

Individual data were missing for the following reasons: the test schedule was not completed, the quality of the data was insufficient for processing (a poor blood pressure signal or arrhythmias) or there were more than $10 \%$ non-sinus beats in the total number of recorded beats.

The study protocol was approved by the Ethics Committee of the Vrije Universiteit Medical Centre. All study participants gave their informed consent.

Participants were asked to refrain from smoking and drinking coffee for $2 \mathrm{~h}$ prior to the assessment of cardiovascular autonomic function. Tests took place between 8:30 am and 4:00 pm, at least $1 \mathrm{~h}$ after a light meal. Subjects were supine resting in a quiet ambience, with a room temperature between 19 and 22 degrees Celsius. Cardiac cycle duration (RR interval) and continuous finger arterial pressure were measured under three conditions: (i) spontaneous breathing (Fig. 1), (ii) six deep breaths over one minute (Fig. 2), and (iii) an active change in position from lying to standing (Fig. 3). The correct frequency of breathing of six breaths per minute was controlled and dictated by oral and visual instructions of the investigator, who followed the beeps generated by the data-acquisition program. When off-line spectral analysis of the systolic blood pressure data showed a clearly recognizable peak shifted from the breathing frequency of $0.10 \mathrm{~Hz}$ by more than $0.02 \mathrm{~Hz}$, the measurements were discarded. After each test a resting period of at least $1 \mathrm{~min}$ was included, to prevent influences by previous test conditions.

During the tests, heart rate and blood pressure were continuously recorded on a PC-based data-acquisition system. RR intervals were obtained from a bipolar ECG chest-lead by a hardware QRS detector with an accuracy of one millisecond. Blood pressure was recorded continuously, using the Finapres method (Finger Arterial Blood Pressure, Ohmeda BP2000), digitally sampled at $200 \mathrm{~Hz}$, and off line low-pass filtered and down-sampled to100 Hz. Beat-to-beat systolic blood pressure values were obtained from this processed blood pressure signal by means of an automatic procedure, which was verified by visual inspection. 

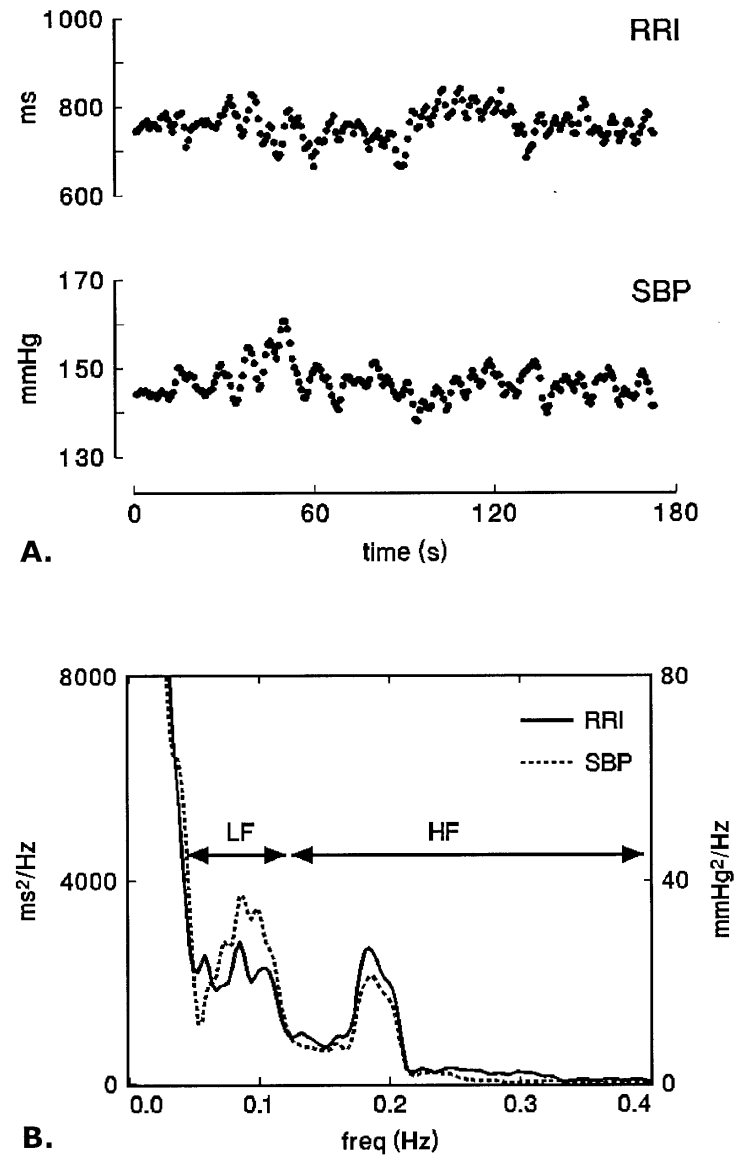

Fig. 1A, B. A typical example of beat-to-beat variations in RR intervals (RRI) and systolic blood pressure (SBP) during 3 minutes of spontaneous breathing in the supine position. Subject is a healthy woman aged 57 years. (A) Variability in the time domain. (B) Variability in the frequency domain, expressed as power spectra; low frequency (LF) and high frequency $(\mathrm{HF})$ band are indicated by horizontal arrows

Ten parameters of cardiac autonomic function were derived from the RR interval and systolic blood pressure recordings obtained during the three respective conditions [37]. During spontaneous breathing over $3 \mathrm{~min}$ in the supine position, the mean (mean NN) and the standard deviation (SDNN) of all normal to normal, i.e. sinus rhythm, RR intervals were computed [41]. Further, the power (variance) in the low frequency (LF) band $(0.04$ to $0.12 \mathrm{~Hz})$ and the power in the high frequency (HF) band $(0.12$ to $0.40 \mathrm{~Hz})$ were assessed from all normal sinus rhythm RR intervals by spectral analysis [41]. Also, the ratio of the LF power to the sum of the $\mathrm{LF}$ and $\mathrm{HF}$ power was calculated [LF/(LF+HF)] [41]. From the recording during six deep breaths over $1 \mathrm{~min}$ in the supine position, we measured the difference in maximum and minimum RR interval duration during expiration and inspiration, and averaged over the six consecutive breaths (EI difference) [3, 42]. Further, a measure of the sensitivity of the spontaneous baroreflex control of heart rate, baroreflex sensitivity (BRS) was calculated by means of cross-spectral analysis. BRS was defined as the change in RR intervals caused by changes in systolic blood pressure $(\mathrm{ms} / \mathrm{mmHg}$ ), and was estimated as the gain of the transfer function between blood pressure and RR interval changes [43, 44]. For the computation of the BRS only spectral components were used that were within a defined band width $(0.05-0.15 \mathrm{~Hz})$ around the
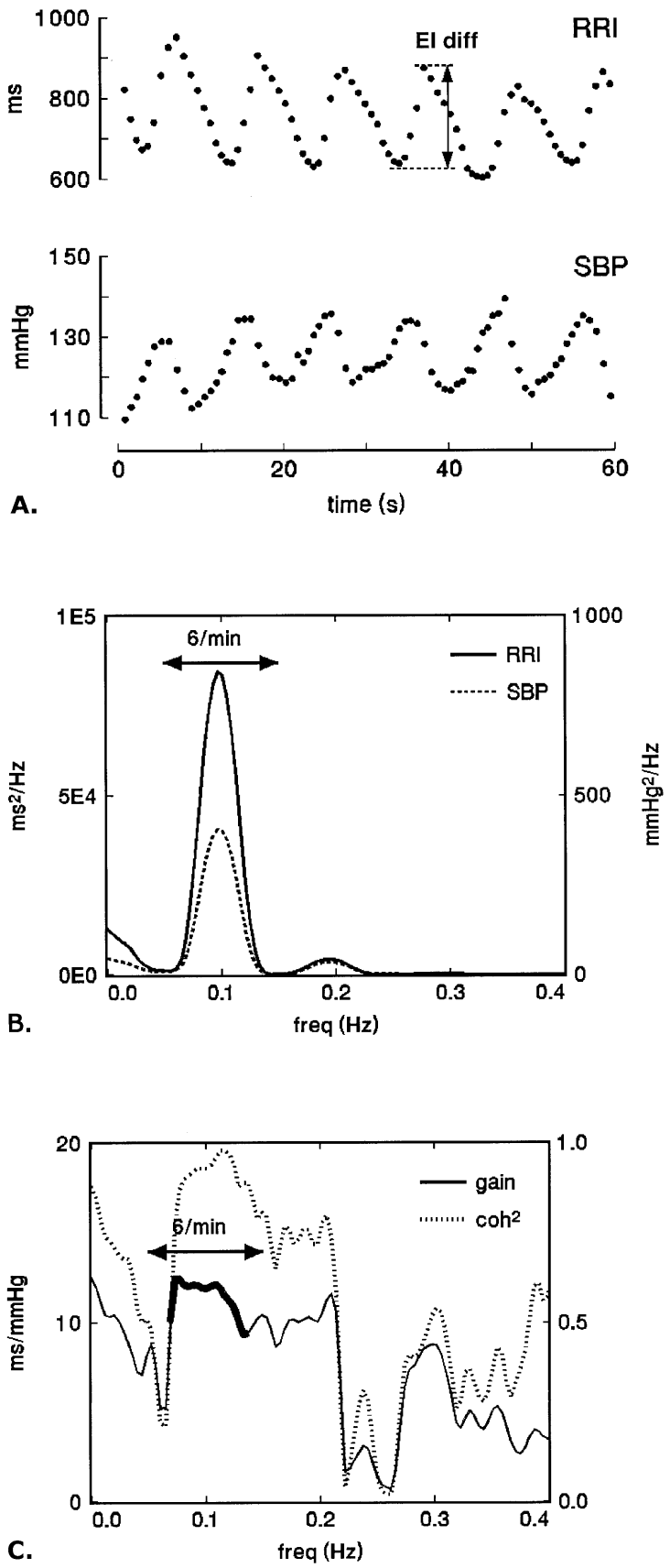

Fig. 2A-C. (A) Typical example of beat-to-beat variations in RR intervals (RRI) and systolic blood pressure (SBP) during one minute deep breathing at 6 breaths per minute. Same subject as in Figure 1. El difference is defined as the difference between maximum and minimum RR interval (indicated by the vertical arrow) averaged over 5-6 consecutive breaths; in this case, $245 \mathrm{~ms}$. (B) Power spectra of the above recordings. Note that most of the power in RRI and SBP variations is concentrated in the one peak at breathing rate $0.1 \mathrm{~Hz}$ (6 per min). (C) Transfer function between SBP and RRI variations. The average value of the bold part of the transfer gain function (continous line) is defined as the baroreflex sensitivity (BRS), in this case, $11.1 \mathrm{~ms} / \mathrm{mmHg}$. Note the high coherence (dotted line) in the respiratory band around $0.1 \mathrm{~Hz}$ (horizontal arrow) 


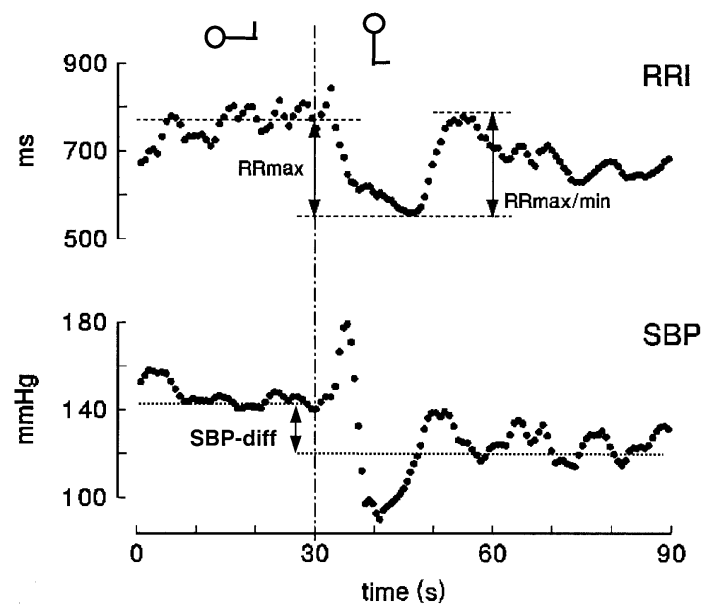

Fig. 3. Typical example of RR intervals (RRI) and systolic blood pressure (SBP) changes during an active change (at $\mathrm{t}=30 \mathrm{~s}$ ) in posture from lying to standing. The three autonomic function measures derived from this test are: RRmax, $\mathrm{RRmax} / \mathrm{min}$ and SBP difference, as is indicated by vertical arrows

breathing frequency of six breaths per minute and with a squared coherence $\left(\gamma^{2}\right)$ of 0.5 or higher. During an active change in position from lying to standing, the maximal change in RR interval (RRmax), defined as the difference between the mean RR interval during 1 min prior to standing up and the minimum RR interval within $15 \mathrm{~s}$ after standing up, was obtained [17]. Furthermore, we measured the maximum RR interval between 15 and $30 \mathrm{~s}$ after standing up divided by the minimum RR interval within $15 \mathrm{~s}$ after standing up (RRmax/min) [45] and the systolic blood pressure difference (SBP difference) after standing up calculated as the mean over $30 \mathrm{~s}$ during 1.5 to $2 \mathrm{~min}$ after standing up, minus the mean over $30 \mathrm{~s}$ prior to standing up [3].

Statistical Analysis. A normal distribution of SDNN, LF power, HF power, EI difference, BRS, RRmax and RRmax/min values was obtained by taking the natural logarithm. Subsequently, for the presentation of the geometric means, standard deviations and percentiles, ln-values were back-transformed. To assess the possible influence of age and sex, the regression model was used: Autonomic function measure $=\alpha+\beta_{1} \cdot$ age $+\beta_{2}$.gender + $\beta_{3} \cdot($ age*sex $)$ or submodels thereof, depending on the outcome of the analysis; with age in decades and sex as a dichotomous variable, $0=$ male and $1=$ female. Logarithmic $(\ln )$ transformation of SDNN, LF power, HF power, EI difference, BRS, RRmax and RRmax/min was carried out to obtain normally distributed residuals. Reference values, defined as the $90 \%$ prediction interval for individual predictions, were computed from the estimated linear regression parameters, thus optimally using the available measurements $[38,46]$.

To assess the agreement between the measures of autonomic function, data from all 631 subjects were used. Spearman's correlation coefficient was computed between all ten measures. The computed reference values were applied and subsequently the percentage of findings concordant for autonomic dysfunction was computed.

For the sample, which had duplicate measurements, the reliability coefficient (RC) and the coefficient of variation (CV) were calculated by analysis of variance to obtain test-retest reliability [47].

$\mathrm{RC}=\mathrm{SD}_{\text {between }}^{2} /\left(\mathrm{SD}^{2}\right.$ between $\left.+\mathrm{SD}^{2}{ }_{\text {within }}\right) * 100 \%$, with high values of $\mathrm{RC}$ representing good reproducibility. $\mathrm{CV}=\mathrm{SD}_{\text {within }}$ '
Table 1. Characteristics and measures of autonomic function of the normotensive study sample $(n=191)$ stratified by sex in a healthy cohort aged 50 to 75 years $^{\mathrm{a}}$

\begin{tabular}{|c|c|c|}
\hline Characteristics & Male $(n=98)$ & Female $(n=93)$ \\
\hline Age (years) & $62.0(7.4)$ & $63.3(7.4)$ \\
\hline BMI $\left(\mathrm{kg} / \mathrm{m}^{2}\right)$ & $25.4(2.5)$ & $25.7(3.5)$ \\
\hline $\begin{array}{l}\text { Fasting plasma glucose } \\
(\mathrm{mmol} / \mathrm{l})\end{array}$ & $5.45(0.51)$ & $5.31(0.49)$ \\
\hline $\mathrm{HbA}_{1 \mathrm{c}}(\%)$ & $5.35(0.50)$ & $5.31(0.43)$ \\
\hline Cholesterol (mmol/l) & $6.47(1.04)$ & $6.67(1.18)$ \\
\hline HDL Cholesterol (mmol/l) & $1.22(0.33)^{\mathrm{c}}$ & $1.55(0.32)^{\mathrm{c}}$ \\
\hline Triglycerides $(\mathrm{mmol} / \mathrm{l})$ & $1.61(0.77)^{\mathrm{c}}$ & $1.27(0.60)^{\mathrm{c}}$ \\
\hline $\begin{array}{l}\text { Diastolic blood pressure } \\
(\mathrm{mmHg})\end{array}$ & $80(7)^{c}$ & $77(7)^{\mathrm{c}}$ \\
\hline $\begin{array}{l}\text { Systolic blood pressure } \\
(\mathrm{mmHg})\end{array}$ & $128(12)$ & $128(13)$ \\
\hline \multicolumn{3}{|l|}{ Autonomic function measures } \\
\hline Mean NN, ms & $989(15)$ & $956(14)$ \\
\hline SDNN, ms b & $36.5(21.4-63.3)$ & $35.4(18.8-57.9)$ \\
\hline LF power, $\mathrm{ms}^{2 \mathrm{~b}}$ & $354(95-1002)^{\mathrm{c}}$ & $213(51-773)^{\mathrm{c}}$ \\
\hline HF power, $\mathrm{ms}^{2} \mathrm{~b}$ & $189(44-995)$ & $175(34-964)$ \\
\hline $\mathrm{LF} /(\mathrm{LF}+\mathrm{HF})$, unitless & $0.59(0.02)$ & $0.54(0.02)$ \\
\hline EI difference, $\mathrm{ms}{ }^{\mathrm{b}}$ & $207(89-385)^{c}$ & $163(73-291)^{\mathrm{c}}$ \\
\hline $\mathrm{BRS}, \mathrm{ms} / \mathrm{mmHg} \mathrm{b}$ & $9.0(4.5-15.4)$ & $8.0(4.3-14.4)$ \\
\hline $\mathrm{RR} \max , \mathrm{ms}^{\mathrm{b}}$ & $269(154-410)$ & $246(162-365)$ \\
\hline $\mathrm{RR}$ max/min, unitless $\mathrm{b}$ & $1.24(1.08-1.51)$ & $1.24(1.10-1.47)$ \\
\hline SBP difference, $\mathrm{mmHg}$ & $-3.8(1.6)$ & $-8.1(1.6)$ \\
\hline
\end{tabular}

a Data are mean (standard deviation) unless otherwise indicated; ${ }^{b}$ Given are the median (10 to $90^{\text {th }}$ percentiles); ${ }^{c}$ Male vs female, $p<0.05$ after correction for age

mean $_{\text {both measurements }} * 100 \%$, with low values representing good reproducibility. For the ratio RRmax/min, the CV was computed using $\left(\right.$ mean $\left._{\text {both measurements }}-1\right)$ as the nominator.

Two-tailed $p$ values of less than 0.05 were considered statistically significant.

\section{Results}

Reference values (in reference sample, $n=191$ ). For none of the autonomic function measures the interaction term between age and sex was statistically significant. After adjustment for age, the regression analysis showed that LF power and EI difference were higher for men than for women (Table 1 and 2). Therefore, sex-specific reference values are presented for these measures. Of the ten autonomic function parameters seven decreased with increasing age, while for mean $\mathrm{NN}, \mathrm{LF} /(\mathrm{LF}+\mathrm{HF})$ and SBP difference no association with age was observed. Therefore, we calculated age-specific reference values for SDNN, LF power, HF power, EI difference, BRS, RR max and RR max/min at 50, 55, 60, 65, 70 and 75 years respectively (Table 2 ).

Agreement (in whole sample, $n=631$ ). The agreement between the ten measures of autonomic function differed widely with correlation coefficients ranging 
Table 2. Reference values for the ten autonomic function parameters as a function of age ${ }^{\mathrm{a}}$. Given are the $90 \%$-prediction intervals for individuals as estimated from a selected healthy normotensive reference sample aged 50 to $75(n=191)$. Also given are the mean (SD) values for the healthy reference sample (second column)

\begin{tabular}{|c|c|c|c|c|c|c|c|c|c|}
\hline \multirow[t]{2}{*}{ Autonomic function measure } & & \multirow[t]{2}{*}{ Mean (SD) } & & \multicolumn{6}{|c|}{ Age (years) } \\
\hline & & & & 50 & 55 & 60 & 65 & 70 & 75 \\
\hline \multirow[t]{2}{*}{$\mathrm{SDNN}, \mathrm{ms}^{\mathrm{b}}$} & & $36.2(19.4-60.5)$ & $5 \%$ & 19.5 & 18.5 & 17.5 & 16.5 & 15.6 & 14.6 \\
\hline & & & $95 \%$ & 82.3 & 77.4 & 72.9 & 68.8 & 65.1 & 61.7 \\
\hline & $\mathrm{F}$ & $213(51-773)$ & $5 \%$ & 56 & 48 & 42 & 36 & 31 & 26 \\
\hline & & & $95 \%$ & 1895 & 1607 & 1369 & 1172 & 1008 & 872 \\
\hline \multirow[t]{2}{*}{ HF power, $\mathrm{ms}^{2} \mathrm{~b}$} & & $183(39-965)$ & $5 \%$ & 48 & 38 & 31 & 25 & 20 & 15 \\
\hline & & & $95 \%$ & 2422 & 1913 & 1518 & 1211 & 972 & 784 \\
\hline \multirow[t]{2}{*}{$\mathrm{LF} /(\mathrm{LF}+\mathrm{HF})$, unitless } & & $0.56(0.01)$ & $5 \%$ & 0.26 & for all & & & & \\
\hline & & & $95 \%$ & 0.85 & for all & & & & \\
\hline \multirow[t]{2}{*}{$\mathrm{BRS}, \mathrm{ms} / \mathrm{mmHg} \mathrm{b}$} & & $8.8(4.5-15.0)$ & $5 \%$ & 4.7 & 4.3 & 4.0 & 3.6 & 3.3 & 3.0 \\
\hline & & & $95 \%$ & 24.3 & 22.0 & 20.0 & 18.3 & 16.7 & 15.3 \\
\hline \multirow[t]{2}{*}{$\mathrm{RR} \max , \mathrm{ms} b$} & & $256(158-393)$ & $5 \%$ & 161 & 154 & 147 & 140 & 133 & 126 \\
\hline & & & $95 \%$ & 492 & 467 & 445 & 424 & 404 & 386 \\
\hline \multirow[t]{2}{*}{$\mathrm{RR} \max / \mathrm{min}$, unitless $\mathrm{b}$} & & $1.24(1.09-1.49)$ & $5 \%$ & 1.13 & 1.09 & 1.06 & 1.03 & 1.00 & 0.97 \\
\hline & & & $95 \%$ & 1.63 & 1.58 & 1.53 & 1.48 & 1.44 & 1.40 \\
\hline \multirow[t]{2}{*}{ SBP difference, $\mathrm{mmHg}$} & & $-5.8(1.1)$ & $5 \%$ & -31 & for all & & & & \\
\hline & & & $95 \%$ & 22 & for all & & & & \\
\hline
\end{tabular}

a For three out of the ten autonomic function parameters no (statistically) significant association with age was observed: mean NN, LF/(LF+HF) and SBP difference. For SDNN, LF power, HF power, EI difference, BRS, RR max and RR $\mathrm{max} / \mathrm{min}$ are reported at 50,55, 60, 65, 70 and 75 years respectively; b $\mathrm{Ln}$ transformed; given are the median $\left(10^{\text {th }}\right.$ to $90^{\text {th }}$ centiles)
Table 3. Agreement between the measures of autonomic function in the complete sample of $n=631$. The upper right part shows the Spearman correlation coefficients. The lower left part gives the percentage of concordant grouping when applying the reference values (lowest $5^{\text {th }}$ centile)

\begin{tabular}{|c|c|c|c|c|c|c|c|c|c|c|}
\hline $\begin{array}{l}\text { Autonomic } \\
\text { function } \\
\text { measures }\end{array}$ & Mean & SDNN & $\begin{array}{l}\text { LF } \\
\text { power }\end{array}$ & $\begin{array}{l}\text { HF } \\
\text { Power }\end{array}$ & $\begin{array}{l}\mathrm{LF} / \\
(\mathrm{LF}+\mathrm{HF})\end{array}$ & $\begin{array}{l}\text { EI } \\
\text { difference }\end{array}$ & BRS & $\begin{array}{l}\mathrm{RR} \\
\max \end{array}$ & $\begin{array}{l}\mathrm{RR} \max / \\
\min \end{array}$ & $\begin{array}{l}\text { SBP } \\
\text { difference }\end{array}$ \\
\hline SDNN & $42 \%$ & & $0.82^{a}$ & $0.80^{\mathrm{a}}$ & -0.07 & $0.52^{a}$ & $0.48^{a}$ & $0.52^{a}$ & $0.41^{\mathrm{a}}$ & $0.16^{\mathrm{a}}$ \\
\hline LF power & $26 \%$ & $56 \%$ & & $0.70^{\text {a }}$ & $0.26^{\mathrm{a}}$ & $0.51^{\text {a }}$ & 0.43 a & 0.45 a & 0.39 a & $0.10^{b}$ \\
\hline HF power & $29 \%$ & $56 \%$ & $52 \%$ & & $-0.46^{a}$ & $0.49^{\text {a }}$ & $0.43^{a}$ & $0.48^{a}$ & $0.40^{\mathrm{a}}$ & $0.13^{\text {a }}$ \\
\hline $\mathrm{BRS}$ & $48 \%$ & $48 \%$ & $38 \%$ & $36 \%$ & $14 \%$ & $63 \%$ & & 0.37 a & $0.31^{\mathrm{a}}$ & 0.06 \\
\hline $\mathrm{RR} \max$ & $87 \%$ & $55 \%$ & $41 \%$ & $41 \%$ & $7 \%$ & $31 \%$ & $31 \%$ & & 0.57 a & $0.16^{a}$ \\
\hline $\mathrm{RR} \max / \min$ & $13 \%$ & $15 \%$ & $16 \%$ & $13 \%$ & $2 \%$ & $17 \%$ & $13 \%$ & $18 \%$ & & 0.05 \\
\hline SBP difference & $0 \%$ & $11 \%$ & $11 \%$ & $3 \%$ & $7 \%$ & $8 \%$ & $8 \%$ & $3 \%$ & $3 \%$ & \\
\hline
\end{tabular}

${ }^{\mathrm{a}} p<0.01 ;{ }^{\mathrm{b}} p<0.05$

from -0.01 to 0.82 and, as assessed by applying the reference values (Table 2) to the total sample $(n=631)$, the percentage of findings concordant for autonomic dysfunction ranged from $0 \%$ to $87 \%$ (Table 3 ). The agreement and correlation coefficient of
$\mathrm{LF} /(\mathrm{LF}+\mathrm{HF})$ and SBP difference with all other autonomic function measures were the lowest. $\mathrm{RRmax} / \mathrm{min}$ also showed a markedly low percentage of concordance with the other measures, while Spearman's correlation coefficients were moderate. For 
Table 4. Reproducibility of ten measures of autonomic function in a sample of $n=36$, taken out of the complete sample of $n=631$ of 50 - to 75-year-old subjects, expressed as the SD within subjects, SD between subjects, reliability coefficient (RC), and coefficient of variation (CV)

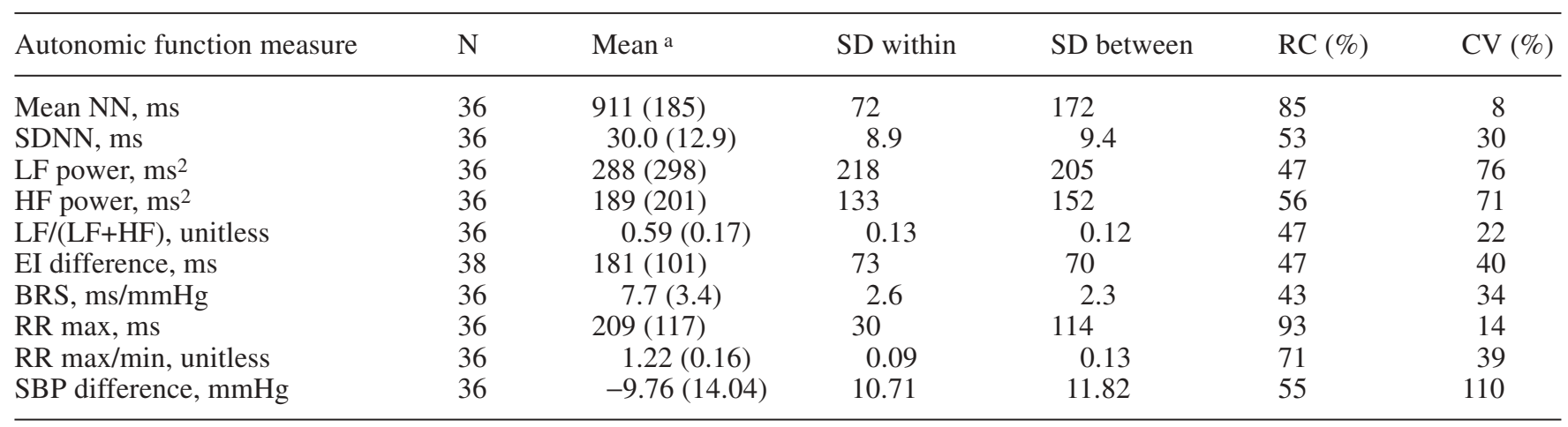

SDNN, LF power, HF power, EI difference, BRS and RRmax agreement was good.

Reproducibility (in reproducibility sample, $n=39$ ). In a subset of the Hoorn Study sample ( $n=36$ to 38 ) from which duplicate measurements were available, the mean values, SD within subjects and SD between subjects, reliability coefficient (RC) and coefficient of variation $(\mathrm{CV})$ were calculated for all autonomic function measures (Table 4). In general, reproducibility of all parameters was moderate to high, with RCs ranging from 43 to $93 \%$ and CVs ranging from 7 to $110 \%$. Mean NN and RRmax had the best reproducibility with a RC over $85 \%$ and CV below $10 \%$.

\section{Discussion}

This study shows data on age-specific and sex-specific reference values as well as reproducibility and mutual agreement of ten measures of autonomic function in adults aged 50 to 75 years. With the exception of two, the agreement between the measures of autonomic function was fairly good.

Reference values. This study, which is based on a screening with repeated oral glucose tolerance tests in a random sample from a well-defined general population. It has, therefore, the major advantage of not including subjects with impaired autonomic function due to impaired glucose tolerance or undiagnosed diabetes mellitus. We excluded subjects with other characteristics known to be associated with impaired autonomic function, i.e. a history of cardiovascular disease, hypertension and use of certain medication, or neurological disease. Moreover, our sample $(n=191)$ includes a substantial number of subjects in a high age category, which has been sparsely shown in previous studies, despite its high relevance in view of the common occurrence of Type 2 diabetes and its complications in this age group. Furthermore, this is the first large study in which three different categories of autonomic function measures were studied simultaneously: Ewing-test measures, heart-rate variability measures and baroreflex sensitivity.

The association between measures of autonomic function and sex is consistent with previous findings: women had lower values of autonomic function [9, 14, 15]. This association was both statistically and clinically significant for LF power and EI difference and appropriate sex-specific reference values were given. Also, the association between measures of autonomic function and age is consistent with previous findings $[8,9,10,11,12,13]$, although we found slightly lower associations with age. This could be attributable to the older age of our subjects compared to previous studies. Our study extends previous findings in a sample of more advanced age.

It has been reported that high values of autonomic function measures also have a predictive value in cardiovascular disease; high values are associated with a higher risk of cardiovascular disease [48]. Therefore, we have provided both the lower and upper reference values. We have computed the reference values on a statistical basis, by taking the upper and lower five percent of individual predictions on the basis of the estimated variances. Ideally, one would define a cutoff value on the basis of subjects who get the disease and those who do not get the disease. In case of autonomic neuropathy however, this is difficult since there is no consensus about the diagnosis of the disease. Nevertheless, several papers call for standardization of measurements $[1,2]$. Furthermore, the two distribution curves of the groups with and without the disease are not likely to be completely separated, and some statistical decision will have to be made eventually. Therefore, the chosen statistical approach is the most feasible with the current knowledge and consensus.

Of course it would be of utmost importance to use the defined criteria to assess the prevalence and incidence of autonomic dysfunction in the general population. However, because the Hoorn Study is an age-, sex- and glucose-tolerance-stratified cohort we were not able to do this. Several other studies [26] would 
provide excellent cohorts to apply these reference values. The predictive value for mortality and morbidity, however, would be more informative, as well as longitudinal observations on changes in autonomic function. Agreement. The agreement, as assessed in the non-selected sample of 631 subjects, varied greatly between the different measures of autonomic function. One prominent finding was the high agreement between SDNN, LF power, BRS and EI difference with the other measures of autonomic function.

The measures derived from the lying-to-standing test, however, did poorly agree with the measures of the other two tests. It could be that the lying-to-standing test depends, more than the other tests, on the patient's co-operation or ability to exert effort. Especially in an elderly population this could be problematic, as is also shown by the higher number of missing values for this test. Poor agreement between heart-rate changes during deep breathing and after standing up has also been reported in a study of 133 healthy subjects in the age range of 10 to 65 years, where they found a correlation between EI difference and RR max of 0.17 and between EI difference and RR max/min of 0.14 [17]. An explanation might be the possible involvement of different afferent and efferent mechanisms [49]. For instance the RRmax/min measure expresses the ratio of the relative bradycardia and the immediate occurring tachycardia after standing up. While the latter is almost exclusively determined by parasympathetic withdrawal, the bradycardia is a rebound effect depending on the presence of a recovery (and overshoot) of blood pressure by sympathetically mediated vasoconstriction [50]. This makes the RRmax/min ratio an autonomic function parameter expressing cardiac vagal as well as (indirect) vasomotor sympathetic functioning, while deep breathing heart rate changes are almost exclusively vagally mediated. Similar arguments as for the RRmax/min, hold for the systolic blood pressure fall after standing up (SBP difference). Moreover, SBP difference probably measures more than just autonomic function, as the compliance of the vascular (venous) system could play a role as well.

Another remarkable observation was the lack of agreement between the spectral HRV power ratio, the $\mathrm{LF} /(\mathrm{LF}+\mathrm{HF})$ measure, and all other measures of autonomic function. In 1986, it was suggested that the instantaneous balance between sympathetic and vagal nerve activities might be captured by a single number [51]. This ratio, or so-called sympathovagal balance, has been embraced by many others, because it would offer "new possibilities for understanding dynamic, critically important autonomic interrelations in humans by use of totally non-invasive, unobtrusive means" [52]. Although applied by many investigators in the field of autonomic neural functioning, the concept of this balance with its lack of a sound physiological basis, also has been seriously criticized $[53,54]$. Our results cast serious doubts on this power ratio as a measure of autonomic function, since it shows little to no agreement with any of the other measures of autonomic function.

Furthermore, we observed that measures obtained from within the same test showed a higher agreement than with those from another test. This is likely due to the fact that these measures are obtained from the same data set. For instance, the SDNN measure is mathematically closely related to the spectral power (the total power equals variance, which is by definition the squared standard deviation); so it is to expect that the SDNN measure taken from the spontaneous three minutes of HRV agrees relatively well with the LF and HF power computed from this same three minutes of HRV data, which indeed it does, given the correlation coefficients of 0.82 and 0.80 , respectively.

We applied two different measures to express the agreement between the autonomic function measures: Spearman's non-parametric correlation coefficients and the percentage of agreement in subjects labelled as having autonomic dysfunction based on the reference values. The latter gives additional information, since correlation coefficient alone strictly speaking gives only the strength of a relation between two variables and not the agreement. [55] Both the correlation coefficients and the percentages of agreement gave very similar results, indicating that the agreement was similar not only in the lower tail of the distribution, but over the entire range.

Reproducibility. In general, reproducibility, as assessed in the subsample of 39 subjects, was moderate to high. For example, the EI difference, the most frequently used measure for autonomic function, had a $\mathrm{RC}$ of $47 \%$ and a CV of $40 \%$. BRS and HRV measures (SDNN, LF power, HF power) showed a comparable reproducibility. These observations are roughly in line with other studies. Best reproducibility was observed for the Mean NN and the RR max with RCs over $85 \%$ and $\mathrm{CV}$ s below $10 \%$. The observed moderate reproducibility could be partly attributable to the advanced age of the subjects in two ways. Firstly, because lower mean values are inherent to higher age which directly leads to higher CVs (see methods section for formula). Secondly, elderly people in general have more difficulties to correctly carry out certain tests (deep breathing and standing up quickly enough). This becomes apparent when comparing our reproducibility with other studies: somewhat higher reproducibility for the deep breathing test (EI difference and BRS) for slightly younger subjects $[12,56,57,58]$. Reproducibility of course might be improved by standardizing the conditions during measurements [56]. In our study measurements took place between 8:30 am and 4:00 pm. Since there was no further standardization regarding time it is possible that diurnal rhythm has influenced the reproducibility to some extent. However it will not have caused a systematic difference, since there was no systematic approach in the sequence of measurements with respect to for example age or glucose tolerance. 
Our reproducibility data are probably more indicative of autonomic function testing in daily clinical practice compared to "clean" laboratory studies and in that sense might be more valuable.

Some earlier attempts have been made to compare classic Ewing tests with some of the new HRV or BRS in studies of autonomic dysfunction in mainly Type 1 diabetes [4, 16, 20, 59]. This study is, however, the first that compares standard Ewing tests, HRV as well as BRS within the same sample at an advanced age and not restricted to diabetic patients. The correlation coefficients and percentage concordance showed that the agreement between the tests was not perfect. This might on one hand be due to the moderate reproducibility and on the other hand different measures could (partly) measure different physiological substrates. In the latter case some measures may be complementary to each other. In view of these results it would be recommended to use a combination of measures to assess autonomic dysfunction.

In conclusion, this study shows that the agreement between eight out of ten measures of cardiovascular autonomic function varied greatly. Application of reference values of autonomic function may be considered for testing autonomic function: age- and sex specific reference values are given for adults aged 50 to 75 years.

Acknowledgements. This study was supported by a grant from the Dutch Diabetes Research Foundation (Diabetes Fonds Nederland).

\section{References}

1. Report and recommendations of the San Antonio conference on diabetic neuropathy. Consensus statement (1988) Diabetes 37:1000-1004

2. Proceedings of a consensus development conference on standardized measures in diabetic neuropathy (1992) Neurology 42:1823-1839

3. Ewing DJ, Martyn CN, Young RJ, Clarke BF (1985) The value of cardiovascular autonomic function tests: 10 years experience in diabetes. Diabetes Care 8:491-498

4. Bellavere F, Balzani I, De Masi G et al. (1992) Power spectral analysis of heart-rate variations improves assessment of diabetic cardiac autonomic neuropathy. Diabetes 41:633-640

5. Frattola A, Parati G, Gamba P et al. (1997) Time and frequency domain estimates of spontaneous baroreflex sensitivity provide early detection of autonomic dysfunction in diabetes mellitus. Diabetologia 40:1470-1475

6. Lishner M, Akselrod S, Avi VM, Oz O, Divon M, Ravid M (1987) Spectral analysis of heart rate fluctuations. A noninvasive, sensitive method for the early diagnosis of autonomic neuropathy in diabetes mellitus. J Auton Nerv Syst 19:119-125

7. Pagani M, Malfatto G, Pierini S et al. (1988) Spectral analysis of heart rate variability in the assessment of autonomic diabetic neuropathy. J Auton Nerv Syst 23:143-153

8. Gribbin B, Pickering TG, Sleight P, Peto R (1971) Effect of age and high blood pressure on baroreflex sensitivity in man. Circ Res 29:424-431
9. Liao D, Barnes RW, Chambless LE, Simpson RJ Jr, Sorlie P, Heiss G (1995) Age, race, and sex differences in autonomic cardiac function measured by spectral analysis of heart rate variability--the ARIC study. Atherosclerosis Risk in Communities. Am J Cardiol 76:906-912

10. Piha SJ (1991) Cardiovascular autonomic reflex tests: normal responses and age- related reference values. Clin Phys 11:277-290

11. O'Brien IA, O'Hare P, Corrall RJ (1986) Heart rate variability in healthy subjects: effect of age and the derivation of normal ranges for tests of autonomic function. British Heart Journal 55:348-354

12. Ziegler D, Laux G, Dannehl K et al. (1992) Assessment of cardiovascular autonomic function: age-related normal ranges and reproducibility of spectral analysis, vector analysis, and standard tests of heart rate variation and blood pressure responses. Diabet Med 9:166-175

13. James MA, Robinson TG, Panerai RB, Potter JF (1996) Arterial baroreceptor-cardiac reflex sensitivity in the elder1y. Hypertension 28:953-960

14. Toyry JP, Niskanen LK, Mantysaari MJ, Lansimies EA, Uusitupa MI (1996) Occurrence, predictors, and clinical significance of autonomic neuropathy in NIDDM. Ten-year follow-up from the diagnosis. Diabetes 45:308-315

15. Huikuri HV, Pikkujamsa SM, Airaksinen KE et al. (1996) Sex-related differences in autonomic modulation of heart rate in middle-aged subjects. Circulation 94:122-125

16. Ziegler D, Dannehl K, Volksw D, Muhlen H, Spuler M, Gries FA (1992) Prevalence of cardiovascular autonomic dysfunction assessed by spectral analysis and standard tests of heart-rate variation in newly diagnosed IDDM patients. Diabetes Care 15:908-911

17. Wieling W, Brederode JF van, Rijk LG de, Borst C, Dunning AJ (1982) Reflex control of heart rate in normal subjects in relation to age: a data base for cardiac vagal neuropathy. Diabetologia 22:163-166

18. Spallone V, Menzinger G (1997) Diagnosis of cardiovascular autonomic neuropathy in diabetes. Diabetes 46: S67-S76

19. Sundkvist G, Lilja B (1985) Autonomic neuropathy in diabetes mellitus: a follow-up study. Diabetes Care 8:129-133

20. Freeman R, Saul JP, Roberts MS, Berger RD, Broadbridge C, Cohen RJ (1991) Spectral analysis of heart rate in diabetic autonomic neuropathy. A comparison with standard tests of autonomic function. Arch Neurol 48:185-190

21. Lanting P, Faes TJC, Heimans JJ, Voorde BJ ten, Nauta JJ, Rompelman O (1990) Spectral analysis of spontaneous heart rate variation in diabetic patients. Diabetic Medicine 7:705-710

22. Weston PJ, James MA, Panerai R et al. (1996) Abnormal baroreceptor-cardiac reflex sensitivity is not detected by conventional tests of autonomic function in patients with insulin-dependent diabetes mellitus. Clin Sci (Colch) 91:59-64

23. Bigger JT Jr, Fleiss JL, Steinman RC, Rolnitzky LM, Kleiger RE, Rottman JN (1992) Frequency domain measures of heart period variability and mortality after myocardial infarction. Circulation 85:164-171

24. La Rovere MT, Bigger JT Jr, Marcus FI, Mortara A, Schwartz PJ (1998) Baroreflex sensitivity and heart-rate variability in prediction of total cardiac mortality after myocardial infarction. Lancet 351:478-484

25. Tsuji H, Venditti FJ Jr, Manders ES et al. (1994) Reduced heart rate variability and mortality risk in an elderly cohort. The Framingham Heart Study. Circulation 90:878-883

26. Dekker JM, Schouten EG, Klootwijk P, Pool J, Swenne CA, Kromhout D (1997) Heart rate variability from short electrocardiographic recordings predicts mortality from all 
causes in middle-aged and elderly men - the Zutphen Study. Am J Epidemiol 145:899-908

27. Savage S, Estacio RO, Jeffers B, Schrier RW (1996) Urinary albumin excretion as a predictor of diabetic retinopathy, neuropathy, and cardiovascular disease in NIDDM. Diabetes Care 19:1243-1248

28. Katsube Y, Saro H, Naka M et al. (1996) Decreased baroreflex sensitivity in patients with stable coronary artery disease is correlated with the severity of coronary narrowing. Am J Cardiol 78:1007-1010

29. Osterziel KJ, Hanlein D, Willenbrock R, Eichhorn C, Luft F, Dietz R (1995) Baroreflex sensitivity and cardiovascular mortality in patients with mild to moderate heart failure. $\mathrm{Br}$ Heart J 73:517-522

30. Lucini D, Pagani M, Mela GS, Malliani A (1994) Sympathetic restraint of baroreflex control of heart period in normotensive and hypertensive subjects. Clin Sci 86: 547-556

31. Schwartz PJ, La Rovere MT, Vanoli E (1992) Autonomic nervous system and sudden cardiac death. Experimental basis and clinical observations for post-myocardial infarction risk stratification. Circulation 85:177-191

32. Lefrandt JD, Hoogenberg K, Van Roon AM, Dullaart RPF, Gans ROB, Smit AJ (1999) Baroreflex sensitivity is depressed in microalbuminuric Type I diabetic patients at rest and during sympathetic manoeuvres. Diabetologia 42: 1345-1349

33. Smulders YM, Jager A, Gerritsen J et al. (2000) Cardiovascular autonomic function is associated with (micro-)albuminuria in elderly Caucasian subjects with impaired glucose tolerance or type 2 diabetes. Diabetes Care 23:1369-1374

34. The Diabetes Control and Complications Trial Research Group (1998) The effect of intensive diabetes therapy on measures of autonomic nervous system function in the diabetes control and complications trial (DCCT). Diabetologia 41:416-423

35. Beks PJ, Mackaay AJ, Neeling JND de, Vries H de, Bouter LM, Heine RJ (1995) Peripheral arterial disease in relation to glycaemic level in an elderly Caucasian population: the Hoorn study. Diabetologia 38:86-96

36. Vegt F de, Dekker JM, Ruhe HG et al. (1999) Hyperglycaemia is associated with all-cause and cardiovascular mortality in the Hoorn population: the Hoorn Study. Diabetologia 42:926-931

37. Gerritsen J, Dekker JM, Tenvoorde BJ et al. (2000) Glucose tolerance and other determinants of cardiovascular autonomic function tests: the Hoorn Study. Diabetologia 43:561-570

38. Gerritsen J, Tenvoorde BJ, Dekker JM, Kostense PJ, Bouter LM, Heethaar RM (2000) Baroreflex sensitivity in the elderly: influence of age, breathing and spectral methods. Clin Sci (Colch) 99:371-381

39. WHO Study Group on Diabetes Mellitus (1985) Diabetes mellitus. Technical Report Series No 727. World Health Organization, Geneva

40. Rose GA, Blackburn H, Gillum RF, Prineas RJ (1982) Cardiovascular Survey Methods. WHO Monograph Series 56. World Health Organization, Geneva

41. Task Force of the European Society of Cardiology and the North American Society of Pacing and Electrophysiology (1996) Heart rate variability: standards of measurement, physiological interpretation and clinical use. Circulation 93:1043-1065

42. Faes TJC, Neeling NN de, Kingma R, Tenvoorde BJ, Karemaker JM (1995) On the quantification of heart rate changes in autonomic function tests: relations between measures in beats per minute, seconds and dimensionless ratios. Clin Sci (Colch) 89:557-564
43. Bendat JS, Piersol AG (1986) Random data analysis and measurement procedures. Wiley, New York

44. Tenvoorde BJ, Faes TJC, Janssen TWJ, Scheffer GJ, Rompelman O (1995) Respiratory modulation of blood pressure and heart rate studied with a computer model of baroreflex control. In: Di Rienzo M, Mancia G, Parati G, Pedotti A Zanchetti A (eds) Computer analysis of cardiovascular signals. IOS Press, Amsterdam, pp 119-134

45. Mackay JD, Page MM, Cambridge J, Watkins PJ (1980) Diabetic autonomic neuropathy. The diagnostic value of heart rate monitoring. Diabetologia 18:471-478

46. Snedecor GW, Cochran WG (1989) Statistical methods. Iowa States University Press, Ames, Iowa

47. Fleiss JL (1986) Reliability of measurement. In: Fleiss JL (ed.) The design and analysis of clinical experiments. Wiley, New York, pp 1-32

48. Dekker JM, Crow RS, Folsom AR et al. (2000) Low heart rate variability in a 2-minute rhythm strip predicts risk of coronary heart disease and mortality from several causes: the ARIC study. Atherosclerosis risk in communities. Circulation 102:1239-1244

49. Bennett T, Farquhar IK, Hosking DJ, Hampton JR (1978) Assessment of methods for estimating autonomic nervous control of the heart in patients with diabetes mellitus. Diabetes 27:1167-1174

50. Wieling W (1988) Standing, orthostatic stress, and autonomic function. In: Bannister R (ed.) Autonomic failure: a textbook of clinical disorders of the autonomic nervous system. Oxford University Press, Oxford, pp 308-320

51. Pagani M, Lombardi F, Guzzetti S et al. (1986) Power spectral analysis of heart rate and arterial pressure variabilities as a marker of sympatho-vagal interaction in man and conscious dog. Circ Res 59:178-193

52. Malliani A, Pagani M, Lombardi F, Cerutti S (1991) Cardiovascular neural regulation explored in the frequency domain. Circulation 84:482-492

53. Parati G, Saul JP, Di Rienzo M, Mancia G (1995) Spectral analysis of blood pressure and heart rate variability in evaluating cardiovascular regulation. A critical appraisal. Hypertension 25:1276-1286

54. Eckberg DL (1997) Sympathovagal balance: a critical appraisal. Circulation 96:3224-3232

55. Bland JM, Altman DG (1986) Statistical methods for assessing agreement between two methods of clinical measurement. Lancet i: 307-310

56. Lawrence GP, Home PD, Murray A (1992) Repeatability of measurements and sources of variability in tests of cardiovascular autonomic function. Br Heart J 68:205-211

57. Lawrence GP, Home PD, Murray A (1992) Autonomic function testing in diabetic subjects using sequential measurements. Diabet Med 9:799-805

58. Herpin D, Ragot S (1997) Mid- and long-term reproducibility of noninvasive measurements of spontaneous arterial baroreflex sensitivity in healthy volunteers. Am J Hypertens 10:790-797

59. Ewing DJ, Borsey DQ, Bellavere F, Clarke BF (1981) Cardiac autonomic neuropathy in diabetes: comparison of measures of R-R interval variation. Diabetologia 21: $18-24$

60. Parati G, Pomidossi G, Ramirez A, Cesana B, Mancia G (1985) Variability of the haemodynamic responses to laboratory tests employed in assessment of neural cardiovascular regulation in man. Clin Sci (Colch) 69:533-540

61. Parati G, Omboni S, Villani A et al. (2001) Reproducibility of beat-by-beat blood pressure and heart rate variability. Blood Press 6:217-220 